\title{
Classroom Engagement and Mathematics Achievement in Senior and Junior High School Students
}

\author{
Sunawan ${ }^{1}$, Halen Dwistia ${ }^{1}$, Kusnarto Kurniawan1, Sri Hartati ${ }^{1}$, Afriyadi Sofyan ${ }^{1}$ \\ 1Department of Guidance and Counseling, Faculty of Education, Universitas Negeri Semarang, \\ Gd. A2 Lt. 1 Kampus Sekaran, Gunungpati, Semarang, Indonesia
}

\begin{abstract}
The purpose of present study was intended to clarify the prediction of classroom engagement on mathematics achievement of senior and junior high school students. A correlational study design was applied with involving a total sample of 368 students (134 junior high school students and 234 senior high school students). Data were collected from Classroom Engagement Inventory and document of students' mathematics achievement and analyzed using moderator analysis technique. The results indicated that only disengagement negatively predicted mathematics achievement, whereas affective engagement, behavior engagement, and cognitive engagement did not significantly predict mathematics achievement. Furthermore, senior high school with lowest level of disengagement has the best opportunity to attain highest mathematics achievement. Discussion of these findings were intended to clarify strengthen and weakness of grading practices in high school.
\end{abstract}

Keywords: Mathematics achievement; classroom engagement; high school students

\section{INTRODUCTION}

Indonesian students' mathematics achievement are important to be investigated because their attainment in mathematics achievement have not yet met the expected standard. Educational statistics data [1] indicated that students' mathematics achievement in National Examination ("Ujian Nasional") in 2014/2015 were in low level $($ mean $=46.41$ ) when compared with other subject matter, such as Bahasa Indonesian $($ mean $=63.56)$, English $(56.80)$, Indonesian literature $($ mean $=64.53)$, and antropology $($ mean $=55.39)$. The survey of PISA in 2012 placed Indonesian students' mathemtics achievement in second lowest ranking (score $=375$ ), whereas Vietnamese students' (score $=511$ ) and other ASEAN countries had higher ranking than Indonesian students' in mathematics [2]. Therefore, present study aimed to identify the role of students' classroom engagement on mathematics achievement.

Related with students' math achievement, recently engagement is an important construct to predict students' learning achievement [3]. Wang [4] defined classroom engagement as a student's active involvement in classroom learning activities, including attention, interest investment, and effort students expend in the work of learning. Students with high level of engagement invest more effort during learning so that they are enable to attain a better achievement. An international study have 
shown that classroom engagement positively predict students' achievement [5]. A study about high school students' engagement and academic achievement is from Reeve and Tseng [6]. The study showed that students' engagement have positive correlation with academic achievement. Unfortunately, the study from Reeve and Tseng [6] only involving Senior High School students and not focus on specific-class phenomenon. To clarify those issues, in present study, classroom engagement was applied to predict students' mathematics achievement for senior high school and junior high school.

Students' engagement, in the classroom, can be classified as affective, behavior, and cognitive engagement [4]. In mathematics class context, affective engagement refers to positive emotions during mathematics class, such as interest, happiness, enjoyment, and enthusiasm. Behavioral engagement refers to observable behavior which is indicated that students are actively involved to mathematics class, such as time-on task, overt attention, classroom participation, completing class exercise, question asking, expressing idea, and choice of challenging tasks. Cognitive engagement refers to students' mental effort to mastery mathematics learning material, such as strategy use, meaningful processing, concentration, self-monitoring, and metacognition. Moreover, disengagement refers to irrelevant behavior and cognitive activities with mathematics learning process.

In this study, classroom engagement was hypothesized to predict mathematics achievement for both Junior and Senior High School students. Specifically, affective engagement (1), behavior engagement (2), and cognitive engagement (3) positively predict mathematics achievement for Junior and Senior High School students. In contrast, disengagement (4) negatively predicts mathematics achievement Junior and Senior High School students.

\section{METHODS}

\section{Participants}

Present study was involved 368 (234 junior high school students and 134 senior high school) Indonesian students as participants. They were randomly selected from three schools of Senior High School (5 classes) and three schools of Junior High School (7 classes).

\section{Measurement}

\section{CLASSROOM ENGAGEMENT}

Students' classroom engagement were assessed by using Classroom Engagement Inventory (CEI) from Wang, Bergin and Bergin [4]. The CEI cosists of 24 items on a 5-point scale for assessing affective engagement (5 items; "I feel excited"), behavioral engagement-compliance behavioral engagement-class participation (5 items; "I get really involved in mathematics class activities"), cognitive engagement ( 8 items; "If I make a mistake, I try to figure out where I went wrong"), and disengagement ( 3 items; "I am "zoned out"; not really thinking or doing class work"). The back-translation procedures were implemented to adapt the 
CEI from English version into Bahasa Indonesian with involving two EnglishBahasa Indonesia interpreters from Centre for Language Training (CLT). The results of exploratory factor analysis and reliability coefficients of the CEI were presented at Table I.

\section{MATHEMATICS ACHIEVEMENT}

The sources of students' mathematics achievement were from the document of student achievement in the second semester of 2016-2017. The records of students' achievement were accessed from the ledger document.

\begin{tabular}{|c|c|c|c|}
\hline Aspects/Items & Loading Factor & \% of Variance & $\alpha$ \\
\hline Affective Engagement & & 46.63 & 0.69 \\
\hline $\mathrm{AE} 1$ & 0.65 & & \\
\hline $\mathrm{AE} 2$ & 0.64 & & \\
\hline $\mathrm{AE} 3$ & 0.76 & & \\
\hline $\mathrm{AE} 4$ & 0.85 & & \\
\hline AE 5 & 0.44 & & \\
\hline Behavior Engagement & & 55.44 & 0.78 \\
\hline BE 6 & 0.77 & & \\
\hline BE 7 & 0.88 & & \\
\hline BE 8 & 0.80 & & \\
\hline BE 9 & 0.69 & & \\
\hline BE 10 & 0.53 & & \\
\hline Cognitive Engagement & & 40.04 & 0.74 \\
\hline CE 11 & 0.61 & & \\
\hline CE 12 & 0.55 & & \\
\hline CE $13^{*}$ & - & & \\
\hline CE 14 & 0.78 & & \\
\hline CE 15 & 0.80 & & \\
\hline CE 16 & 0.63 & & \\
\hline CE 17 & 0.41 & & \\
\hline CE 18 & 0.57 & & \\
\hline Disengagement & & 53.13 & 0.64 \\
\hline DE 19 & 0.67 & & \\
\hline DE 20 & 0.81 & & \\
\hline DE 21 & 0.70 & & \\
\hline
\end{tabular}

* The item number of \#13 was deleted in this study because it was not valid

\section{RESULTS}

\section{Descriptive Analysis}

As seen in Table 2, affective engagement, behavior engagement, and cognitive engagement were relatively consistent to have positive correlation with mathematics achievement both for participants from Senior High School $(\mathrm{r}=0.17, \mathrm{p}<0.01 ; \mathrm{r}=$ $0.37, \mathrm{p}<0.01$; and $\mathrm{r}=0.42, \mathrm{p}<0.01$, respectively) and Junior High School $(\mathrm{r}=0.12$, $\mathrm{p}<0.01 ; \mathrm{r}=0.35, \mathrm{p}<0.01 ; \mathrm{r}=0.36, \mathrm{p}<0.01$, respectively). Moreover, only disengagement negatively predicted students' mathematics achievement (for Senior 
High School students: $r=0.26, p<0.01$; for Junior High School students: $r=-0.22$, $\mathrm{p}<0.01)$. The level of Senior and Junior High School students' engagement were not signitificantly different, except behavior engagement and disengagement. Senior High School students $(\mathrm{M}=4.03, \mathrm{SD}=0.59)$ had significantly higher level of behavior engagement than Senior High School students $(M=3.30, S D=0.72 ; t$ $(367)=3.11, \mathrm{p}<0.01)$. However, Senior High School students $(\mathrm{M}=1.91, \mathrm{SD}=$ 0.60 ) had significantly lower level of disengagement than students from Junior High School $(\mathrm{M}=2.04, \mathrm{SD}=0.57$; $\mathrm{t}(367)=-2.09, \mathrm{p}<0.05)$.

TABLE 2. INTER-CORRELATION MATRICES, MEAN AND SD OF CLASSROOM ENGAGEMENT AND ACHIEVEMENT

\begin{tabular}{|c|c|c|c|c|c|c|}
\hline & & 1 & 2 & 3 & 4 & 5 \\
\hline 1. Ach & & & $0.12 * *$ & $0.35 * *$ & $0.36^{* *}$ & $-0.22 * *$ \\
\hline 2. AE & & $0.17 * *$ & & $0.25^{* *}$ & $0.70 * *$ & $-0.45^{* *}$ \\
\hline 3. $\mathrm{BE}$ & & $0.37 * *$ & $0.28 * *$ & & $0.35 * *$ & $-0.68 * *$ \\
\hline 4. CE & & $0.42 * *$ & $0.70 * *$ & $0.30 * *$ & & $-0.44 * *$ \\
\hline 5. DE & & $-0.26 * *$ & $-0.54 * *$ & $-0.61 * *$ & $-0.40 * *$ & \\
\hline Senior High & M & 78.12 & 4.22 & 4.03 & 4.34 & 1.91 \\
\hline School & SD & 3.98 & 0.49 & 0.59 & 0.50 & 0.60 \\
\hline Junior High & M & 78.14 & 4.25 & 3.30 & 3.89 & 2.04 \\
\hline School & SD & 2.69 & 0.49 & 0.72 & 0.55 & 0.57 \\
\hline t (367) & & $-0,04$ & -0.60 & $3.11 * *$ & 0,8 & $-2.09 *$ \\
\hline Total & M & 78.13 & 4.25 & 3.88 & 3.91 & 1.99 \\
\hline foral & SD & 3.21 & 0.49 & 0.68 & -0.53 & 0.58 \\
\hline
\end{tabular}

Note: Inter-correlation matrices for junior high school students $(\mathrm{n}=234)$ are presented above the diagonal, and inter-correlation matrices for junior high school students $(n=134)$ are presented below the diagonal. $\mathrm{Ach}=$ mathematics achievement; $\mathrm{AE}=$ affective engagement; $\mathrm{BE}=$ behavior engagement; $\mathrm{CE}=$ cognitive engagement; $\mathrm{DE}=$ disengagement

$* \mathrm{p}<0.05 \quad * * \mathrm{p}<0.01$

\section{Classroom Engagement Predictors of Mathematics Achievement}

TABLE 3 MODERATOR EFFECT OF SCHOOL ON CORRELATION BETWEEN CLASSROOM ENGAGEMENT AND MATHEMATICS ACHIEVEMENT

\begin{tabular}{|lrrrr|}
\hline \multicolumn{1}{r}{ Predictors } & Coefficients (SE) & \multicolumn{1}{c}{ t } & LLCI (95\%) & ULCI (95\%) \\
\hline AE & $0.38(1.10)$ & 0.35 & -1.79 & 2.56 \\
S & $0.78(2.76)$ & 0.28 & -4.66 & 6.21 \\
AE x S & $-0.11(0.65)$ & -0.16 & -1.38 & 1.17 \\
\hline BE & $1.24(0.94)$ & 1.32 & -0.61 & 3.08 \\
S & $2.65(2.04)$ & 1.30 & -1.36 & 6.65 \\
BE x S & $-0.58(0.51)$ & -1.15 & -1.58 & 0.41 \\
\hline CE & $1.13(1.15)$ & 0.99 & -1.12 & 3.39 \\
S & $2.76(2.45)$ & 1.12 & -2.07 & 7.58 \\
CE x S & $-0.58(0.62)$ & -1.00 & -1.84 & 0.60 \\
\hline DE & $-3.86(0.94)$ & $-4.11^{* *}$ & -5.71 & -2.02 \\
S & $-1.86(1.11)$ & -1.68 & -4.04 & 0.32 \\
DE x S & $1.13(0.55)$ & $-2.07^{*}$ & 0.05 & 2.20 \\
\hline
\end{tabular}

Notes: $\mathrm{AE}=$ affective engagement; $\mathrm{BE}=$ behavior engagement; $\mathrm{CE}=$ cognitive engagement; $\mathrm{DE}=$ disengagement; $\mathrm{S}=$ school level

$* \mathrm{p}<0.05 \quad * * \mathrm{p}<0.01$ 
Moderator analysis was implemented to clarify the moderator effect of level of educationa on the correlation between classroom engagement with mathematics achievement. Data analysis were performed using SPSS version 21 and PROCESS ${ }^{\circledR}$ syntax from Hayes [7]. The results of moderator analysis were presented at Table 3.

As shown in Table 3, affective engagement, behavior engagement, cognitive engagement, and school were not significantly predict students' mathematics achievement. These findings were against hypothesis 1, 2, and 3. However, as expected in hypothesis 4, disengagement negatively predicted students' mathematics achievement (coefficient $=3.86, \mathrm{t}=-4.11, \mathrm{p}<0.01$ ). Moreover, there was a moderator effect of school level on correlation between disengagement and students' mathematics achievement (coefficient $=1.13, \mathrm{t}=-2.07, \mathrm{p}<0.05$ ). A moderator effect of school indicated the existence of interaction effect of school level and disengagement. That interaction effect was explained that senior high school students who had lowest level of disengagement were predicted highest mathematics achievement than senior high school with medium or low level of disengagement and junior high school in all level disengagement. In contrast, senior high school students who had highest level of disengagement were predicted lowest mathematics achievement (see Figure 1).

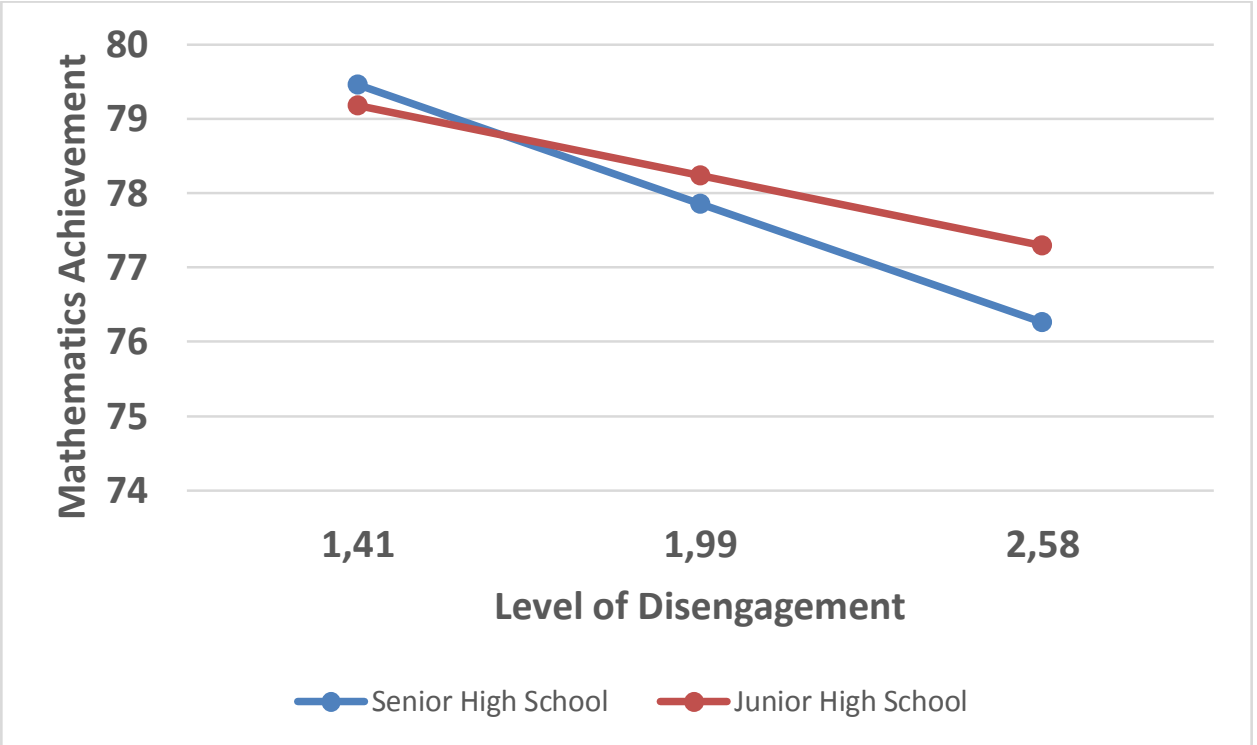

Figure 1 Impact of level engagement on achievement for Senior and Junior High School

\section{DISCUSSION}

Present study was intended to clarify the impact of classroom engagement on mathematics achievement for senior high school and junior high school students. A moderator analysis showed that only disengagement negatively predicted mathematics achievement, whereas affective engagement, behavior engagement, and cognitive engagement did not significantly predicted mathematics achievement. Interestingly, present study also showed the difference correlation between disengagement and mathematics achievement for senior high school and junior high school. 
Present findings were contrast with previous studies which showed that students' engagement was associated with higher achievement [5, 8]. Generally, students' affective, behavior and cognitive engagement affect achievement [9], whereas present finding showed that students' disengagement were negatively associated with mathematics achievement.

Findings of present study reflected Indonesian teachers' expectation on grading, including grading students' mathematics achievement. Indonesian teachers grades students' mathematics achievement based on their disengagement. The higher the level of education, the higher the teachers' focus of mathematics grading based on the level of disengagement. Implicitly, Indonesian teachers' grading not only intended to provide feedbacks on students' learning performance, but also oriented to motivate students conducted appropriate behavior during class.

Indonesian teachers' grading standards which lay on the disengagement are different with previous findings. A study from Kaiser, Retelsdorf, Südkamp, and Möller [9] showed that students' engagement, including affective, behavior and cognitive engagement, had a positive and significant correlation with teachers' judgment on students' achievement. As implications, Indonesian teachers need to change their standard on grading from students' disengagement to students' engagement. Furthermore, the study of Indonesian teachers grading are needed to be investigated, particularly the contribution of culture on grading.

\section{CONCLUSIONS}

Present study indicated that disengagement negatively predict mathematics achievement, whereas affective, behavior and cognitive engagement were not significantly predicted mathematics achievement. Moreover, there was a differences correlation between students' disengagement and mathematics achievement for senior high school and junior high school.

Recommendation for teaching practices are: (1) teacher should consider students' engagement during class as one of component of evaluation judgment, and (2) students' appropriate behavior should be appreciated in a proportional credit because the main purpose of teaching in school is students' learning. For further study, it can be recommended to clarify remain questions such as: (1) what do affect students' engagement and achievement? (2) how are the grading practice of Indonesian teachers? (3) are the grading system affected by culture?

\section{REFERENCES}

[1] Puspendik Kemdikbud RI. 2015. Laporan Hasul Ujian Nasional. Jakarta: Depdikbud. Available at http://118.98.234.50//hun/statistik.apx.

[2] OECD. 2014. PISA 2012 Results in Focus: What 15-year-olds know and what they can do with what they know. [online]. Available at http://www.oecd.org/pisa.

[3] Lan, X., C.C. Ponitz, K.F. Millera, S. Li, K. Cortina, M. Perry, \& G. Fang. 2009. Keeping their attention: Classroom practices associated with behavioral engagement in first grade mathematics classes in China and the United States. Early Childhood Research Quarterly, 24, 198-211. doi: 10.1016/j.ecresq.2009.03.002. 
[4] Wang, Z., C. Bergin, \& D.A. Bergin. 2014. Measuring engagement in fourth to twelfth grade classrooms: The Classroom Engagement Inventory. School Psychology Quearterly, 28(4), 1-19. doi: $10.1037 / \mathrm{spq} 0000050$.

[5] Lam, S., et al. 2012. Do girls and boys perceive themselves as equally engaged in school? The results of an international study from 12 countries. Journal of School Psychology. 50, 77-94. doi: 10.1016/j.jsp.2011.07.004

[6] Reeve, J., \& Tseng, C.M. 2013. Agency as a fourth aspect of students' engagement during learning activities. Contemporary Educational Psychology. 36, 257-267. doi: 10.1016/j.cedpsych.2011.05.002.

[7] Hayes, A. F. 2013. PROCESS for SPSS 2.16.1 [software]. Available at www.afhayes.com or processmacro.org.

[8] Reyes, M.R., M. A. Brackett, S. E. Rivers, M. White, \& P. Salovey. 2012. Classroom emotional climate, student engagement, and academic achievement. Journal of Educational Psychology. 104(3), 700-7012. Doi: 10.1037/a0027268.

[9] Kaiser, J., J. Retelsdorf, A. Südkamp, \& J. Möller. 2013. Achievement and engagement: How student characteristics influence teacher judgments. Learning and Instruction 28, 73-84. Doi: 10.1016/j.learninstruc.2013.06.001. 